\title{
A AMEAÇA À REFUNDAÇÃO DO ESTADO BOLIVIANO: FRAGILIDADE INSTITUCIONAL E INSTABILIDADE POLÍTICA*
}

\author{
La amenaza a la refundación del Estado boliviano: \\ fragilidad institucional e inestabilidad política \\ The threat to the refoundation of the Bolivian state: \\ institutional fragility and political instability
}

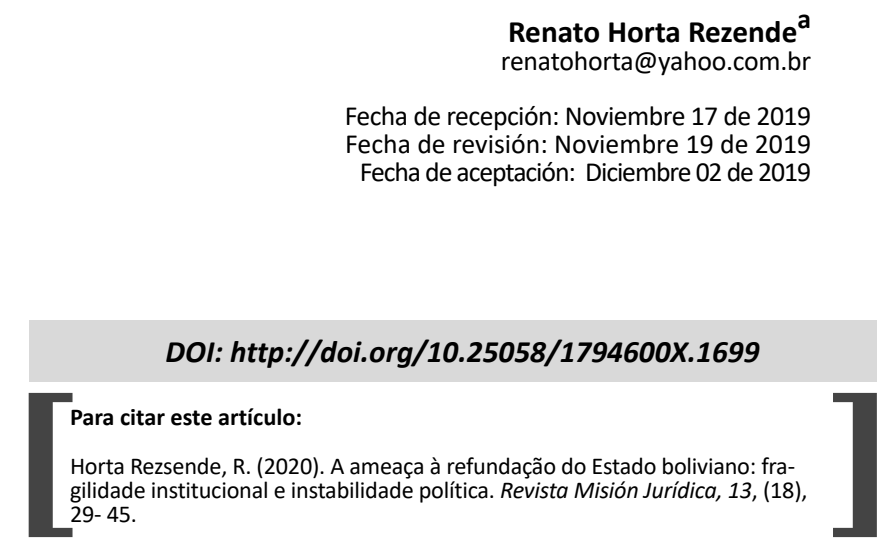

\section{RESUMO}

O novo constitucionalismo democrático latino-americano, em construção no subcontinente, pretende reajustar concepções monistas e colonizadoras que não se apresentaram por séculos como a melhor alternativa para a região. A Constituição Política da Bolívia de 2009, que reconheceu a plurinacionalidade e o desejo em refundar um Estado afastado de concepções colonizadoras, possuem diversos desafios dentre os quais a tensão gerada entre o desejo das oligarquias em manter o poder e o autoritarismo das novas lideranças políticas, fato que repercute no questionamento acerca da capacidade do novo constitucionalismo democrático latino-americano e do Estado Plurinacional boliviano de fortalecer as instituições democráticas. Por meio do método de pesquisa hipotético-dedutivo, examinou-se a existência de um novo constitucionalismo adequado para a região; o estágio ainda em construção do desenvolvimento de novo paradigma na Bolívia e a incapacidade atual do Estado Plurinacional e da teoria do novo constitucionalismo latino-americano de fortalecer as instituições democráticas. Todas as hipóteses foram confirmadas.

\footnotetext{
*Artículo de reflexión.

a. Professor de disciplinas afins ao Direito no Centro Universitário UNA (2018 até os dias atuais); Professor do Curso de Direito na Faculdade Pitágoras (2018-2019); Professor do Curso de Direito da FACISA/MG (2018); Diretor da Comissão de Direito das Famílias da OAB-Minas (2019-2021); Mestre em Direito pelo Programa de Pós-graduação em Direito da Universidade Fumec (2016); Especialização em ciência criminais na Faculdade Arnaldo Janssen (2018); graduado em Direito pela Fundação Universidade de Itaúna (2004); Advogado inscrito na Seccional Minas Gerais há treze anos (2005); Professor do CEB-CECON (2007-2011); Professor no CFDs da APMMG (2014); Professor de arbitragem, mediação e conciliação junto ao Conselho Estadual de Arbitragem de Minas Gerais (2009-2018), Árbitro inscrito no CONFEJAB (2015); escritor de livro e vários artigos científicos.
} 


\section{PALAVRAS-CHAVES}

Constitucionalismo

latino-americano; Estado Plurinacional da Bolívia; instabilidade institucional; plurinacionalidade.

\section{RESUMEN}

El nuevo constitucionalismo democrático latinoamericano, en construcción en el subcontinente, pretende reajustar las concepciones monistas y colonizadoras que, durante siglos, no han sido la mejor alternativa para la región. La Constitución Política de Bolivia de 2009, que reconoció la plurinacionalidad y el deseo de refundar un estado lejos de las concepciones colonizadoras, tiene varios desafíos, incluida la tensión generada entre el deseo de las oligarquías de mantener el poder y el autoritarismo de los nuevos líderes políticos. Este hecho afecta la capacidad del nuevo constitucionalismo democrático latinoamericano y del Estado Plurinacional boliviano para fortalecer las instituciones democráticas. A través del método de investigación hipotéticodeductivo, se examinó la existencia de un nuevo constitucionalismo adecuado para la región; la etapa, aún en construcción, del desarrollo de un nuevo paradigma en Bolivia y la incapacidad actual del Estado Plurinacional y la teoría del nuevo constitucionalismo latinoamericano para fortalecer las instituciones democráticas. Todas las hipótesis han sido confirmadas.

\section{PALABRAS CLAVES}

Constitucionalismo

latinoamericano; Estado Plurinacional de Bolivia; Inestabilidad institucional; plurinacionalidad.

\section{ABSTRACT}

0 presente documento trata do conceito de resThe new Latin American democratic constitutionalism, under construction in the subcontinent, seeks to readjust monist and colonizing conceptions that, for centuries, have not shown themselves to be as the best alternative for the region. The Bolivian Political Constitution of 2009, which recognized plurinationality and the desire to refound a state away from colonizing conceptions, has several challenges, including the tension generated between the desire of the oligarchies to maintain power and the authoritarianism of new political leaders. This affects the capacity of the new Latin American democratic constitutionalism and the Bolivian Plurinational State to strengthen democratic institutions. Through the hypothetical-deductive research method, the existence of a new constitutionalism suitable for the region was examined; the stage still under construction of the development of a new paradigm in Bolivia and the current inability of the Plurinational State and the theory of the new Latin American constitutionalism to strengthen democratic institutions. All hypotheses have been confirmed.

\section{KEYWORDS}

Latin American constitutionalism, Plurinational State of Bolivia, institutional instability; plurinationality.

\section{INTRODUÇÃO}

0 processo de redemocratização dos Estados latino-americanos iniciado na década de oitenta do século XX não foi concluído com o fim das ditaturas militares que vigoraram na região, se apresentando como processo contínuo, lento e expansivo de decolonização político, jurídico e cultural de reconhecimento de minorias e radicalização da legitimidade democrática.

Na última década, reformas e Constituições foram promulgadas no subcontinente com o objetivo teleológico de ampliar o processo de decolonização e maximizar a emancipação sobre concepções que parecem inadequadas à região.

A Constituição Política da Bolívia (CPB), ratificada no referendo de 23 de janeiro de 2009 cunhada sob esses auspícios, pretendia, depois de séculos de tentativas mal sucedidas, alterar o modelo constitucional homogêneo radicalizando a democracia, reconhecendo minorias e seus direitos com a finalidade de se adequar às peculiaridades do país.

Todavia, as ações políticas que se seguiram após a promulgação da CPB avultam dúvidas sobre a capacidade do novo constitucionalismo democrático latino-americano e o recém fundado Estado Plurinacional boliviano fortalecem as instituições democráticas de poder historicamente frágeis na América Latina. 
Identificado o problema de cunho teórico e dogmático a ser investigado do ponto de vista especulativa, a presente pesquisa se desenvolve sobre três hipóteses. A primeira é a existência de uma construção de um novo constitucionalismo na Bolívia; a segunda hipótese trata do modelo constitucional boliviano como algo em desenvolvimento sendo decisivo o fortalecimento das instituições democráticas de poder em seus momentos iniciais para consolidação futura; e ainda, como terceira hipótese, em virtude da instabilidade histórica da região, que o novo constitucionalismo democrático latino-americano não é suficiente para conter os atentados contra as instituições democráticas na Bolívia.

A pesquisa tem como objetivo a análise dogmática, histórica e crítica do texto constitucional, normas infraconstitucionais e infralegais, bem como decisões proferidas pela Corte Constitucional boliviana, sendo o estudo desenvolvido com suporte em coleta de dados e decisões publicadas em repositórios oficiais, assim como levantamento da literatura jurídica nacional e estrangeira necessária à compreensão acerca dos temas atinentes ao problema exposto e hipóteses propostas, buscando inicialmente a apresentação de premissas gerais confiáveis com a finalidade de alcanças resultados específicos.

Frente ao acima descrito, tem-se que o método que proporciona a base lógica da investigação proposta é o hipotético dedutivo empregado por meio de combinações de técnicas de observação e antecipação hipotética capaz de alcançar postulados que direcionados ao problema são testados como forma de alcançar respostas suficientes ainda que provisórias. (Gil, 2008: 12-13).

$\mathrm{Na}$ pesquisa desenvolvida, a metodologia desenvolvida não é considerada como apenas um conjunto de técnicas para construção do trabalho científico (Gutin e Dias, 2002), pois incorpora à dimensão teórica dada à investigação, por meio de uma construção histórica como a proposta por Roberto Gargarella na obra referência a este trabalho, La sala de máquinas de la Constitución: dos siglos de constitucionalismo em América Latina (1810-2010).

Pretendendo examinar o problema conforme método e técnica acima estabelecida, colocando à prova as hipóteses, a pesquisa é dividida em três partes, que coincidem com os capítulos seguintes, sendo eles: transição ao novo constitucionalismo democrático latino-americano; o Estado boliviano e a refundação do Estado Plurinacional; e, por fim, o projeto de perpetuação no poder de Evo Morales versus o golpe de Estado que atentam contra o modelo de Estado Plurinacional e o novo constitucionalismo democrático latino-americano.

\section{Transição ao novo constitucionalismo democrático latino-americano ${ }^{1}$}

0 constitucionalismo desenvolvido na modernidade possui origem nas revoluções burguesas dos séculos XVII e XVIII (Fioravanti, 2001: 132) ocorridas na Inglaterra, França e Estados Unidos da América (EUA) que desafiaram o antigo regime ${ }^{2}$, sendo fruto da revolução a supremacia da lei e o desenvolvimento dos direitos fundamentais, capazes de limitar o poder até então absoluto do soberano (Alves, 2013: 107). Mesmo possuindo origens revolucionárias, Canotilho (2003: 51) destaca que o desenvolvimento do constitucionalismo se deu de forma diferente nas três nações citadas, podendo ser singularizado o modelo inglês historicista; francês, individualista; e norte-americano, estadualista.

As experiências constitucionais desenvolvidas na Europa e nos Estados Unidos da América se converteram em teorias hegemônicas, tidas como parâmetros a servir de fundamento para todo o mundo civilizado (Avritizer, 2017: 7). A concepção monista, uniformizadora e universalista, introduzida na América Latina desconsiderou a cultura, a história e costumes dos povos originários ${ }^{3}$, e, mesmo após o processo de independência ${ }^{4}$ das ex-colônias, não se promoveu

1. Outros nomes também são atribuídos ao mesmo movimento conforme o enfoque desejado por seus idealizadores, tais como: "Constitucionalismo transformador ou de baixo" (SANTOS, 2010) $e$ "Constitucionalismo pluralista ou intercultural" (WOLKMER 2009). Nesta pesquisa utilizou-se o termo "democrático latinoamericano" com o objetivo de explicitar o caráter democrático forte e a região em que se desenvolve.

2. Cabe esclarecer que a origem do movimento constitucionalista moderno não se confunde com a origem da própria Constituição, isto porque, a depender das características admitidas, é possível afirmar que sempre houve Constituição (Sampaio, 2013: 28).

3. Evidentemente, mesmo diante da violência do colonizador sempre houve resistência ao processo de dominação nas Américas (Dan e Nascimento, 2016: 352).

4. Excetuando o Brasil, cujo libertador possuía origem nobre, as demais independências da região foram conquistadas pela elite criolla, formada por espanhóis aristocratas nascidos na América que, apoiados por EUA e Inglaterra, aproveitaram a oportunidade criada com o enfraquecimento da metrópole, devida a invasão napoleônica, para promover rebeliões armadas 
a ruptura definitiva com o constitucionalismo hegemônico (Gargarella e Courtis, 2009: 2). 0 constitucionalismo do norte global concebido como adequado a todo o ocidente, parte da concepção da existência de um espaço geopolítico homogêneo em que as diferenças étnicas, culturais ou regionais devem ser ignoradas ou suprimidas dentro do território bem delimitado que o atribui autonomia externa e soberania interna, esta última exercida por instituições centrais que cobrem todo o território monopolizando o sistema legislativo e jurídico coercitivo (Santos, 2010: 70-71).

A manutenção pós-independência do constitucionalismo "universal" monista se desenvolveu nos países latino-americanos como um "arremedo da experiência constitucional dos Estados Unidos da América” (Avritzer, 2017a: 8) sem maiores observâncias relacionadas ao desejo social, pois o objetivo inicial era criar estruturas sólidas a arrimar o próprio Estado, agora independente. 0 constitucionalismo liberal, pós-independência atendia ao triplo objetivo da revolução, independência, limitação da soberania e garantia de direitos fundamentais, mantendose os demais elementos jurídicos, políticos e sociais. 0 fortalecimento do Estado pósindependência atendeu aos desejos das elites que pretendiam a organização do poder do Estado e a manutenção dos elementos básicos de um sistema democrático formal. Contudo, isso não significou estabilidade na região frustrando a promessa do constitucionalismo hegemônico. A instabilidade e o protagonismo do Executivo sobre os demais Poderes na América Latina (Soares e Ladeira, 2013: 3), assim como a ausência da soberania material popular, rechaçada com extrema violência, se traduziram em autoritarismo excludente que nunca deixou de existir na região (Serrano, 2016: 15-16).

O Constitucionalismo social, iniciado com as revoluções da primeira metade do século $\mathrm{XX}$ na Europa reorganizou o período anterior, impondo obrigações intervencionistas ao

voltadas à independência (Vicentino e Dorigo, 2013: 194). Excetuando o Brasil, cujo libertador possuía origem nobre, as demais independências da região foram conquistadas pela elite criolla, formada por espanhóis aristocratas nascidos na América que, apoiados por EUA e Inglaterra, aproveitaram a oportunidade criada com o enfraquecimento da metrópole, devida a invasão napoleônica, para promover rebeliões armadas voltadas à independência (Vicentino e Dorigo, 2013: 194).
Estado com a finalidade de alcançar a isonomia material. A alteração do foco não teve o condão de alterar as diretrizes do constitucionalismo moderno hegemônico justamente porque os direitos de segunda e terceira dimensões ${ }^{5}$ foram desenvolvidos sobre o eixo lógico e ideológico subordinados aos direitos de primeira dimensão (Tarrega e Freitas, 2017: 104) ao qual foi atribuída a insígnia de universal, que, em todo caso, tem como objetivo a limitação do poder soberano e a garantia de direitos reconhecidos como fundamentais pelo Estado.

Em meados do século $\mathrm{XX}$, o movimento constitucional surgido na Europa no período pós-Segunda Grande Guerra passou a atribuir força normativa ao texto constitucional com o objetivo de garantir efetivação e proteção dos direitos reconhecidos como fundamentais. Com isso, a Constituição passou a ocupar o centro do ordenamento jurídico, passando a ser fonte irradiante de preceitos normativos e axiológicos a vincular tanto o poder público como particulares ${ }^{6}$.

A força normativa colhida da Constituição fortaleceu a metáfora do contrato social, bem como a preocupação com a legitimidade, a universalização do constitucionalismo ocidental europeu e, também, o constitucionalismo monista, porém, desta vez, mediada através de ajustes morais impostos ao direito positivo por meios democráticos indispensáveis à concretização dos direitos fundamentais (Ferejohn e Pasquino,

5. Foi utilizada a nomenclatura "dimensões" quando do trato dos direitos fundamentais em reverência aos argumentos de Ingo Wolfgang Sarlet (2007, p. 55): "Em que pese o dissídio na esfera terminológica, verifica-se crescente convergência de opiniões no que concerne à ideia que norteia a concepção das três (ou quatro, se assim preferirmos) dimensões dos direitos fundamentais, no sentido de que estes, tendo tido sua trajetória existencial inaugurada com o reconhecimento forma nas primeiras Constituições escritas dos clássicos direitos de matriz liberal-burguesa, se encontram em constante processo de transformação, culminando com a recepção, nos catálogos constitucionais e na seara do Direito Internacional, de múltiplas e diferenciadas posições jurídicas, cujo conteúdo é tão variável quanto as transformações ocorridas na realidade social, política, cultural e econômica ao longo dos tempos. Assim sendo, a teoria dimensional dos direitos fundamentais não aponta, tãosomente, para o caráter cumulativo do processo evolutivo e para a natureza complementar de todos os direitos fundamentais, mas afirma, para além disso, sua unidade e indivisibilidade no contexto do direito constitucional interno e, de modo especial, na esfera do moderno 'Direito Internacional dos Direitos Humanos."

6. Segundo Cambi (2009: 29), as dimensões horizontais e verticais dada aos direitos fundamentais atribui a estes o poder de traçar o caminho a ser construído no futuro e constitui característica de um constitucionalismo dirigista. 
2009: 53). 0 fortalecimento da Constituição enquanto conjunto de normas cogentes impactou e ampliou o poder da jurisdição constitucional. Consequentemente pôde ser observada certa redução da intervenção do Executivo $^{7}$ no Judiciário. Isso ampliou as prerrogativas do Poder Judiciário e o desvinculou da dominação das estruturas oligárquicas legislativas.

A aproximação do Direito e moral alterou a perspectiva constitucionalista, pois, conceitos axiológicos passaram a limitar a ação ou inação estatal, exigindo-se observação aos princípios e regras constitucionais com a finalidade de conferir legitimidade formal e substancial às normas,sob pena de serem consideradas inválidas no marco constitucional (Renato Horta, 2017: 42). Ainda que se tenha alterado a perspectiva, o movimento neoconstitucionalista manteve a sistemática jurídico-monista, mesmo passando a defender que o Estado constitucional "não é apenas o que conta com um texto que se autodenomina Constituição, mas sim o que conta com uma Constituição fruto da legitimidade democrática e dotada de instrumentos garantidores da limitação do poder e da efetividade de direitos" (Tarrega e Freitas, 2017: 105). 0 importante movimento que atribuiu força normativa ao texto constitucional, aliado ao modelo de Estado Democrático de Direito condicionou a validade das escolhas estatais a construção democrática das decisões, contudo, tal perspectiva não alterou os fundamentos do constitucionalismo moderno se mostrando como uma evolução do mesmo paradigma monista vigente desde as Revoluções Liberais.

Adverte Boaventura de Sousa Santos (2010: 67) que os modelos de Estado, liberal, social de direito, colonial ou de ocupação, soviético, nazifascista, burocrático-autoritário, desenvolvimentista, de apartheid, secular, religioso e de mercado nunca abandonaram a concepção monista e centralizadora do Estado. Contudo, com a redemocratização da América Latina no final do século $\mathrm{XX}$, a participação dos destinatários

7. No período de 1930 até 1988 no Brasil, Colômbia, Bolívia, Equador e Venezuela houve diversas rupturas constitucionais com predomínio do Executivo e baixas prerrogativas ao Judiciário; porém, entre 1988 e 2009, em Brasil, Colômbia $e$ Bolívia as prerrogativas e independência do Judiciário foram ampliadas, enquanto no Equador apesar de ter suas prerrogativas ampliadas permanece subordinada ao Executivo e na Venezuela há a predominância do Executivo com grande intervenção no judiciário (AVRITZER, 2017b, p. 36). como condição para conferir legitimidade à decisão estatal fez surgir o constitucionalismo democrático em seu sentido forte, não sendo mais suficiente a universalidade do sufrágio como condição à legitimidade democrática, pois o cidadão passa a ser coparticipe do projeto de vida em que, liberdade, igualdade e democracia são condições para validar estruturalmente as decisões estatais (RENATO HORTA, 2017:43).

Ocorre que a condição democrática à legitimidade e a força normativa constitucional, ainda assim não se mostravam suficientemente adequadas às ex-colônias ibéricas, isso porque a independência ocorrida no século XIX não refletiu na emancipação monocultural, política e econômica que excluíram comunidades originárias do continente, bem como pobres de origem escrava ou imigrante que, somados, constituem grande parcela da população da região. Os traços de colonialismo e dependência estiveram presentes, em maior ou menor grau, em todas as ex-colônias de Portugal e Espanha na América.

$\mathrm{Na}$ década de noventa do século $\mathrm{XX}, \mathrm{O}$ constitucionalismo democrático forte assumiu na América Latina radicalização que redundou na alteração do modelo constitucional hegemônico, centrado na figura do Estado uniformizador e única fonte válida de decisões voltadas a limitar tanto a soberania popular como o próprio Poder através de outro Poder (PASTOR, DALMAU, 2010: 16).

Em oposição ao constitucionalismo moderno, o novo constitucionalismo democrático Latino Americano não limita, mas reconhece e efetiva a soberania popular jamais exercida materialmente na América Latina. 0 movimento busca inserir excluídos, promovendo e reconhecendo a interlegalidade, admitindo a pluralidade de fontes jurídicas e a participação social direta nas decisões do Estado, fortalecendo o viés normativo atribuído à Constituição pelo movimento neoconstitucional.

Para consecução das pretensões, o novo constitucionalismo democrático latino-americano ampliou fortemente as prerrogativas do Judiciário e das Cortes constitucionais, principalmente no Brasil, Colômbia e Bolívia, e, parcialmente em países como Argentina e Equador, na busca pelo maior equilíbrio entre os poderes, afastando 
as oligarquias que dominam o Legislativo e a predominância do Executivo (AVRITZER, 2017b: 37-38).

Contudo, a pretensão de afastar oligarquias que sempre estiveram no controle do poder estatal traz inúmeros conflitos que somados à instabilidade histórica da política na região cria, permanentemente, estado de tensão propício a radicalismos e retomadas que ameaçam a democracia na região.

O novo constitucionalismo democrático que vem sendo desenvolvido na América Latina, apesar de integrar países pertencentes à mesma dimensão geográfica e possuidores de histórias semelhantes, não vem se aperfeiçoando de forma simétrica sendo possível observar também momentos de regressão e contradição (JIMENEZ, 2012: 19). Contudo, segundo Tarrega e Freitas (2017: 107), é possível identificar, até o momento, três ciclos do novo constitucionalismo democrático latino-americano, sendo a primeira fase marcada pelo forte caráter socializante e reconhecedor de direitos coletivos e plurais, a exemplo da Constituição brasileira de 1988 e colombiana de 1991; uma segunda fase caracterizada pelo constitucionalismo participativo e pluralista, como verificado na Constituição venezuelana de 1999; e a atualmente, uma terceira fase marcada pelo constitucionalismo plurinacional identificado como um modelo não universal e único de Estado de Direito, reconhecedor da coexistência de experiências interculturais, plurais além da isonomia jurisdicional, reconhecendo e integrando a epistemologia de povos no aparelhamento estatal como o desenhado na Constituição boliviana de 2009 .

0 atual estágio do novo constitucionalismo latino-americano, que tem como uma de suas referências o constitucionalismo plurinacional em desenvolvimento na Bolívia, possui inúmeros desafios diante da superação de anos de cultura colonialista, exclusão de povos originários e afrodescendentes, bem como a necessidade de equalizar diversidades culturais conflituosas presentes em arenas políticas e jurídicas, assim como o desejo latente das oligarquias em retomar o controle político-estatal excludente e tradicionalmente dominante em conflito com novas lideranças políticas desejosas em perpetuar no poder.

\section{0 Estado boliviano e a refundação do Estado Plurinacional \\ O território da Bolívia está localizado no} centro-oeste da América do Sul, delimitado ao norte e a leste pelo Brasil, ao sul pelo Paraguai e pela Argentina, e, ao oeste pelo Chile e Peru, tendo se tornado independente em 06 de agosto de 1825. A população boliviana é de 10.969.649 habitantes, $33,5 \%$ com idade máxima de quatorze anos; 61,8\% com idade compreendida entre quinze a sessenta e quatro anos; e, 4,7\% com mais de sessenta e cinco anos, composta, genericamente, por quatro grandes grupos étnicos ${ }^{8}$, sendo eles, 26\% declarados indígenas; 68\% mestiços (brancos e ameríndios); 5\% brancos; e 1\%, negros (CIA, 2017).

A república da Bolívia (art. 11, I da CPB) se constitui em Estado Plurinacional ${ }^{9}$ que reflete o lento e contínuo processo de evolução e involução frente à decolonialização iniciada com a primeira Constituição Política da Boliviana de 19 de novembro de 1826 enviada por Simón Bolívar e aprovada com pequenas alterações pela Assembleia Popular, seguida por outras dezesseis ${ }^{10}$ Constituições $^{11}$ que refletem a instabilidade

8. Cf: Convenção 169 da Organização Internacional do Trabalho (OIT).

9. A Constituição Política boliviana de 2009 não concede nome ao Estado como as Constituições anteriores, sendo sua denominação determinada pelo Decreto Supremo no 0048, de 18 de março de 2009, que renomeou o Estado como, Estado Plurinacional da Bolívia.

10. Em 1994 e em 2004 foram aprovadas profundas reformas na Constituição da República da Bolívia, sendo tais reformas compreendidas por alguns autores como materialmente outra Constituição, compreensão contida no Portal do Governo Boliviano ao qual não é compartilhada nesta pesquisa que reconhece como Constituições somente aquelas derivadas de Poder Constituinte Originário, excluídas outras oriundas do Poder Constituinte Reformador.

11. Em sua história pós-independência, a República da Bolívia contou com dezessete Constituicões, sendo elas:

Constituição Vitalícia ou Bolivariana, de 19 de novembro de 1826; Constituição Política da Bolívia de 14 de agosto de 1831 Constituição da República da Bolívia de 16 de outubro de 1834; Constituição da República da Bolívia de 26 de outubro de 1939 Constituição da República da Bolívia de 11 de junho de 1843; Constituição da República da Bolívia de 20 de setembro de 1851 Constituicão da República da Bolívia de 29 de julho de 1861; Constituição da República da Bolívia de 17 de setembro de 1868; Constituiçãa da República da Bolívia de 9 de outubro de 1871; Constituição da República da Bolívia de 14 de fevereiro de 1878, Constituição da República da Bolívia de 17 de outubro de 1880 Constituição da República da Bolívia de 30 de outubro de 1938; Constituição da República da Bolívia de 24 de novembro de 1945: Constituição da República da Bolívia de 26 de novembro de 1947; Constituição da República da Bolívia de 4 de agosto de 1961; Constituição Política do Estado da Bolívia de 2 de fevereiro 
política marcada por golpes e contragolpes. Os inúmeros golpes de Estado refletem o delicado convívio histórico da Bolívia com a democracia, assim como a força de ingerência da elite interna e internacional que refletiu em um quadro político instável (Silva Júnior, 2014: 285).

0 atual Estado Plurinacional boliviano é soberano, regido pelo modelo de Estado Unitário, Social de Direito Plurinacional Comunitário, como declarado no art. 1ำ da Constituição Política da Bolívia, de 07 de fevereiro de 2009 (CPB). 0 modelo de Estado boliviano reúne quatro elementos de diferentes períodos histórico, social e político, decorrentes da tradição liberal, do Estado de bem-estar, assim como a visão comunitária indígena e reivindicações sociais anteriores a sua promulgação. 0 referido modelo de Estado declara a manutenção da forma de Estado concebida desde a independência boliviana, Estado Unitário. 0 Estado unitário boliviano é desconcentrado (art. 1ํ da CPB), sendo também reafirmando a forma liberal de Estado Social, priorizando interesses coletivos e reconhecendo institucionalmente, a pluralidade e a autonomia das nações originárias (IDEA Internacional, 2010: 210). Ainda na parte dogmática da atual Constituição, em que são apresentadas as bases fundamentais do Estado, a Bolívia concebe o regime de governo democrático participativo, representativo e comunitário (art. 11, I da CPB); o sistema de governo presidencialista (art. 27 da CPB), bem como o reconhecimento de trinta e sete idiomas oficiais (art. 5, I da CPB), dentre os quais o castelhano e outros trinta e seis línguas de origem indígena.

O Estado boliviano é resultado de correlações de forças e de lutas sociais que sempre estiveram presentes no território e foram intensificadas nos últimos anos em toda a América Latina, em especial, na Bolívia. Este aspecto histórico encontra-se estampado no preâmbulo da Constituição boliviana, quando declara que:

O povo boliviano, de composição plural, desde a história antiga, inspiradas nas lutas do passado; no levante indígena anticolonial; na independência; nas lutas de libertação populares; nas marchas indígenas, sociais e sindicais; nas guerras pela água e pelo gás, nas lutas pela terra e território, e pela

de 1967; e Constituição Política da Bolívia, de 7 de fevereiro de 2009. memória de nossos mártires, nós construímos um novo Estado ${ }^{12}$ (tradução livre).

Até a Constituição anterior, Constituição Política do Estado da Bolívia, de 02 de fevereiro de 1967, o Estado boliviano era configurado como um estado monocultural constituído ainda que fictamente por uma massa homogênea de cidadãos governados por seus representantes ${ }^{13}$ e "controlado pela minoria branca que assumiu o controle do Estado e não possibilitou a democratização de setores fundamentais na sociedade" (SILVA JÚNIOR, 2014: 33). Os demais povos não eram identificados em sua singularidade na Constituição, sendo as comunidades indígenas, quando não invisíveis, identificadas como organizações camponesas ${ }^{14}$ e não povos ou nações originárias. A opção por não utilizar o termo "indígena" possuía fundamento na concepção de Estado-Nação em que não se aceitava a coexistência de múltiplas etnias e culturas conviventes no Estado, fato que gerava a negação, exclusão e preconceito, que também não admitia a partição de indígenas ou suas instituições na organização do Estado (Mosiño, 2017: 289).

No final da década de 1990, influenciados por movimentos democráticos do subcontinente Americano e o reconhecimento internacional dos direitos indígenas ${ }^{15}$, organizações étnicas e políticas indígenas camponesas organizaram-se com a finalidade de pressionar o Estado e toda a sociedade não indígena boliviana a reconhecer tanto os povos originários como suas organizações como integrantes do Estado e não como elementos apartados, ou pertencentes a uma mesma etnia ou

12. "El pueblo boliviano, de composición plural, desde la profundidad de la historia, inspirado em las luchas del pasado em la sublevación indígena anticolonial, em la independencia em las luchas populares de liberación, em las marchas indígenas, sociales y sindicales, em las guerras del agua y de octubre, em las luchas por la tierra y territorio, y com la memoria de nuestros mártires, construímos un nuevo Estado." (Bolívia, 2009).

13. "Art. 1. Forma de Estado y de Gobierno Bolivia, libre, independiente y soberana, constituída en República unitaria, adopta para su gobierno la forma democrática representativa. Art. 2. Soberanía y Poderes del Estado

La soberanía reside em el pueblo; es inalienable e imperceptible; su ejercicio está delegado a los poderes Legislativo, Ejecutivo y Judicial." (BOLÍVIA, 1967)

14. "Art. 171.Organizaciones campesinas El Estado reconoce y garantiz a la existencia de las organizaciones sindicales campesinas." (BOLÍVIA, 1967)

15. Cf: Convenção 169 da OIT, de 27 de junho de 1989. 
ainda como simples camponeses. Organizados, em 15 de agosto de 1990, aproximadamente trezentos indígenas marcharam em direção à cidade de La Paz, em movimento conhecido como a Primeira Marcha Indígena pelo Território e Dignidade exigindo o reconhecimento legal de seus territórios (até então de domínio da Nação) ${ }^{16}$, o reconhecimento de suas autoridades e da organizações tradicionais indígenas camponesa (Santander, 2012: 17). Santander (2012) destaca que a Primeira Marcha chamou atenção do mundo para os problemas indígenas na Bolívia e obteve relativo sucesso diante da edição de quatro Decretos ${ }^{17}$ que reconheceram territórios indígenas, além da inserção da causa na agenda política do Estado.

A inserção da causa indígena na pauta governamental redundou na Reforma constitucional de 1994, por meio da Lei no 1.585, de 12 de agosto, que promoveu, dentre inúmeras alterações, a inserção, no artigo primeiro da Constituição, o fato do Estado boliviano se constituir em uma nação multiétnica e pluricultural ${ }^{18}$. Contudo, apesar do reconhecimento e integração dos indígenas ao Estado boliviano como sujeitos coletivos, o mesmo não aconteceu com suas organizações, que permaneciam fora da configuração estrutural do Estado apesar de reconhecidas por este (Mosiño, 2017: 289).

A luta pelo reconhecimento e integração indígena movimentou outras Marchas em direção à cidade de La Paz mediante reunião de novas pautas que não se resumiam mais ao reconhecimento indígena como povo boliviano e o direito ao território de seus ancestrais, mas exigiam também representatividade

16. “Art. 165. Dominio originario de la Nación

Las tierras son del domínio originario de la Nación y corresponde al Estado la distribución, reagrupamiento y redistribución de la propiedad agraria conforme a las necesidades económicosociales y de desarrollo rural" (BOLÍVIA, 1967).

17. Decreto Supremo $n^{-}$22610, que reconheceu o Parque Nacional lsiboroSécure; Decreto Supremo $n^{\circ}$ 22611, que reconheceu os territórios indígenas multiétnicos; Decreto Supremo ${ }^{\circ}$ 2261, que reconheceu o território indígena Chiman; e o Decreto Supremo no 22609, que reconheceu o território indígena Sirionó.

18. "art. 1o - Bolivia, libre, independiente, soberana, multiétnica y pluricultural, constituída en República unitaria, adopta para su gobierno la forma democrática representativa, fundada en la unión y lasolidaridad de todos los bolivianos" (BOLÍVIA, 1994). política e execução de tratados internacionais sobre assuntos indígenas a que a Bolívia tinha aderido $^{19}$. No ano seguinte à eleição do primeiro presidente de origem indígena camponesa, Juan Evo Morales Ayma (Movimiento al Socialismo MAS), foi também eleita a Assembleia constituinte com o objetivo de redigir a décima sétima Constituição Boliviana, aprovada, inicialmente, pela Assembleia Constituinte em 21 de outubro de $2008^{20}$, confirmada pelo referendo realizado em 25 de janeiro de 2009.

No discurso de convocação do referendo para ratificação da Constituição Política da Bolívia, o Presidente explicitou que:

Historicamente, a Bolívia foi construída a partir da exclusão de povos indígenas. É por isso que no marco das transformações profunda e democráticas nós temos proposto mudar esta situação.

Todos que nascemos na Bolívia somos originários dessa terra; alguns somos originários milenares e outros são originários contemporâneos ${ }^{21}$ (tradução livre).

Assim, a Constituição Política da Bolívia de 2009 deixou para trás o Estado multiétinico plural e passou a definir o país como um Estado plurinacional $^{22}$, inserindo tal qualificação em seus órgãos, Assembleia Legislativa Plurinacional (art. 145 da CPB), Governo Plurinacional (art. 5ํ, II da CPB), Tribunal Constitucional Plurinacional (art. 196 da CPB) e Órgão Eleitoral Plurinacional

19. As referidas reivindicações foram apresentas nas segunda, terceira, quarta e quinta Marcha Indígena, realizadas, respectivamente, em 1996, 2000, 2002 e 2006 (SANTANDER 2013, p. 17-18)

20. A aprovação do texto constitucional em 9 de dezembro de 2007 sofreu forte resistência de grupos oposicionistas que apontavam ilegalidades e ausência de participação no processo (EXTRA, 2007)

21. "Históricamente, Bolivia se ha construido a partir de la exclusión de los pueblos indígenas. Es por eso que en el marco de las transformaciones profundas y democráticas nos hemos propuesto cambiar esta situación injusta.

Todos quien es nacimos en Bolivia somos originarios de esta tierra; algunos somos originarios milenários y otros son originarios contemporâneos" (EVO MORALES, 2009).

22. “Artícuo1. Bolivia se constituye en un Estado Unitario Social de Derecho Plurinacional Comunitario, libre, independiente, soberano, democrático, intercultural, descentralizado y con autonomías. Bolivia se funda en la pluralidad y el pluralismo político, económico, jurídico, cultural y lingüístico, dentro del proceso integrador del país"' (BOLÍVIA, 2009). 
(art. 205 da CPB) 23. Mosiño (2017: 291) adverte que a mudança da denominação do Estado de República da Bolívia para Estado Plurinacional da Bolívia, definido no Decreto Supremo no 0048, de 18 de março de 2009, trouxe muitas críticas e grande preocupação, contudo, tornou evidente a conotação política e a intenção de demonstrar formalmente o argumento de refundação do Estado pretendendo afastar o que fez parte do passado como se inválido fosse.

A refundação do Estado encarada como luta não se traduz apenas em sua concepção política, mas também social, cultural, simbólica, mental, habitual e subjetiva por uma nova hegemonia em que a pluralidade e a interculturalidade venham a ser a regra (Santos, 2010: 68).

0 reconhecimento de nações e suas autonomias dentro do Estado exigiu também o desenvolvimento de critérios a adequar a interculturalidade e a necessária complementariedade, assim como determinar postura ativa a proporcionar a desconstrução cultural colonialista mais excludente e impositiva, dentro das estruturas orgânicas do Estado. 0 novo modelo de Estado repercute na administração da Justiça que além de independente, imparcial, segura, transparente, proba, célere, gratuita e equitativa, também deve se ater à participação social, ao pluralismo jurídico e a interculturalidade, em todas as suas jurisdições, ordinária, agroambiental, indígena originária camponesa ou especializada, nos termo do art. 178 da CPB.

O pluralismo jurídico gera, como efeito, a consagração do pluralismo de fontes jurídicas ${ }^{24}$, aspecto que implica na superação monista, possuindo o Estado Plurinacional da Bolívia como primeira fonte direta de Direito a Constituição e, também como fonte direta, as leis infraconstitucionais estatais no mesmo nível hierárquico que os procedimentos e normas produzidas pelas nações e povos IOC.

O pluralismo, que é o elemento estruturante da refundação do novo Estado da Bolívia, exige harmonia e coesão entre as fontes jurídicas por

23. A Constituição Política de 2009 reconheceu quatro Poderes, sendo eles: Executivo, Legislativo, Judiciário e Eleitoral (MACHICADO, 2009, p. 43).

24. Vide art. 3‥9 da Lei no 025 de 24 de junho de 2010. meio da admissão intercultural do conhecimento, que está assente a "expressão e convivência da diversidade cultural, institucional, normativa e linguística, e o exercício dos direitos individuais e coletivos na busca pelo bem estar" (art. 179.10 da Lei 025/2010).

Assim, passam a conviver normas de caráter positivo e consuetudinário, integrando de forma cooperativa e coordenada o Poder Judiciário, composto pelo órgão judicial, integrado pelas Jurisdições, Ordinária, Agroambiental, Indígena Originária Camponesa e especializadas conforme a lei, e o Tribunal Constitucional Plurinacional (TCP).

0 reconhecimento pelo Judiciário de normas positivadas e não necessariamente positivadas representa a aplicação e demonstração do significado do pluralismo definidor da refundação do Estado Plurinacional da Bolívia tratandose de um processo altamente dinâmico diante dos diferentes espaços jurídicos, da ausência de sincronismo entre as jurisdições que integram o Órgão Judicial e o conflito que as diferenças podem causar (Santos, 1988:164), somente passíveis de serem contornados com o reconhecimento da interculturalidade. Essa dimensão jurídica pluralista retira do Estado o monopólio tanto da produção legislativa como jurisdicional, não sendo mais o Estado o único centro produtor e definidor de normas jurídicas, as quais também poderão ter origem em grupos sociais diferenciados (Machicado, 2009: 39).

Com a finalidade de conciliar a pluralidade de fontes jurídicas e jurisdicionais confirmada no texto constitucional, o Estado boliviano sustenta no art. 8.II do mesmo diploma o princípio da complementariedade em que se reconhece as fontes e as jurisdições como autônomas porém interdependentes, atribuindo caráter interlegal ao direito. Tanto a pluralidade como a interculturalidade exprimem um dos objetivos do Estado Plurinacional da Bolívia, explicitado no art. 9.1 da CPB, cuja aplicação constitui desafio perene.

Ainda que a CPB tenha alterado profundamente as estruturas do Estado reconhecendo povos marginalizados e os integrando na estrutura estatal, como também reduziu o poder político oligárquico dominante, fato que repercutiu em descontentamento da elite boliviana, o 
fato de exigir integração e a manutenção de instituições organizadas como na época da colonização retardam o processo de ampliação democrática e geram incongruências sistêmicas, fato que pode não ser suficiente para alterar a "casa de máquinas" a que Gargarella (2015) faz menção, justamente por não ser capaz de afastar completamente as forças políticas tradicionais e tampouco o desejo arbitrário de perpetuação no poder dos governantes que entrelaçam seus desejos com a estrutura organizacional do Estado.

3. 0 projeto de perpetuação no poder de Evo Morales versus o golpe de Estado que atentam contra o modelo de Estado Plurinacional e o novo constitucionalismo democrático latino-americano

Evo Morales e Álvaro Garcia Linera, ambos membros do partido político Movimento ao Socialismo (MAS), foram eleitos, respectivamente como Presidente e Vice-Presidente da República da Bolívia, na eleição realizada em dezembro de 2006, cujo mandato concluiu em 2010. Com a promulgação da CPB em 07 de fevereiro de 2009, o Presidente e o Vice-Presidente eleitos sobre o regime anterior permaneceram em seus cargos até a conclusão do mandato, como previsto no inciso II da primeira disposição transitória da CPB.

Concluído o primeiro mandato em dezembro de 2009, tanto o Presidente como o Vice-Presidente se candidataram à reeleição imediata e, portanto, ao segundo mandato consecutivo, primeiro sobre o novo paradigma de Estado unitário social de direito plurinacional comunitário. Contudo, depois de transcorrido mais da metade do segundo mandato, os parlamentares do MAS apresentaram à Assembleia Legislativa Plurinacional, presidida pelo Vice-Presidente da República, Projeto de Lei (PL) buscando regulamentar, dentre outras disposições constitucionais, também a norma fixada no art. 168 da CPB e no inciso II da primeira disposição transitória, que tratam, respectivamente, da possibilidade de apenas uma reeleição imediata ao cargo de Presidente e Vice da República e da contagem dos mandatos anteriores ao marco constitucional de 2009.

Segundo o art. $4^{\mathrm{o}}$ do $\mathrm{PL}^{25}$, o limite estabelecido no art. 168 e o inciso II da primeira disposição

25. “Artículo 4.- (Reelección del Presidente y Vicepresidente del Estado) transitória da $\mathrm{CPB}$, que veda a possibilidade de duas reeleições consecutivas para o cargo de Presidente e Vice-Presidente da República, somente teria início com o marco constitucional de 2009, ou seja, a partir de janeiro de 2010, enquanto o cômputo do mandato não seria aplicado ao cargo eletivo presidente constitucional (Bolívia, 2013).

O PL teve grande repercussão, primeiramente porque inexistia previsão para a propositura da espécie normativa a regulamentar a referida norma constitucional, a qual foi apresentada como "Ley de Aplicación Normativa"; em segundo lugar porque o Projeto de Lei possuía normatividade individual e concreta, voltado especificamente para o caso do Presidente e Vice-Presidente da República em exercício; e ainda, porque o referido Projeto padeceria de inconstitucionalidade material contrariando a literalidade dos art. $168^{26}$ combinado com o inciso II da primeira disposição transitória ${ }^{27}$, ambos da atual Constituição Política da Bolívia (Horbach, 2015).

Buscando trazer maior segurança jurídica à futura recandidatura, o Vice-Presidente da República, exercendo as funções de Presidente da Assembleia Legislativa Plurinacional, realizou consulta ao Tribunal Constitucional Plurinacional acerca da constitucionalidade do Projeto de Lei de aplicação normativa. Na Declaração Constitucional no 003 proferida em 25 de abril de 2013 (TCP), no controle consultivo prévio de constitucionalidade, o TCP reconheceu a existência de normas constitucionais de aplicação plena e de integração, em que a primeira teria sua aplicação direta e imediata, enquanto a segunda possuiria lacuna presumida e, portanto,

\footnotetext{
I. De conformidad a lo establecido en el Artículo 168 de la Constitución Política del Estado, el Presidente y Vicepresidente elegidos por primera vez a partir de la vigencia de la Constitución, están habilitados para una reelección por una sola vez de manera continua.

II. La prescripción contenida en la Disposición Transitoria Primera, Parágrafo II, de la Constitución Política del Estado, es aplicable a las autoridades que después del 22 de enero de 2010, continuaron ejerciendo cargos públicos, sin nueva elección designación o nombramiento".
}

26. "Artículo 168. El periodo de mandato de la Presidenta o del Presidente y de la Vicepresidenta o del Vicepresidente del Estado es de cinco años, y pueden ser reelectas o reelectos por una sola vez de manera continua" (CPB, 2009).

27. "II. Los mandatos anteriores a la vigencia de esta Constitución serán tomados en cuenta a los efectos del cómputo de los nuevos períodos de funciones" (CPB, 2009). 
exigiria para a sua materialização o complemento legislativo.

Apesar da semelhança com a teoria apresentada por Celso Ribeiro Bastos (2010: 66) em análise à aplicação das normas constitucionais brasileiras, o TCP não se utilizou dos mesmos critérios para definir quais as normas careceriam de integração ${ }^{28}$. Isso porque, de forma unânime, entendeu a Corte que todas as normas que compõe a parte dogmática da $\mathrm{CPB}$, localizado entre o art. $1^{\mathrm{o}}$ e art. 147, possuiriam aplicação direta e imediata, enquanto os demais dispositivos careceriam de integração normativa para adquirirem eficácia plena. Observa-se que o critério utilizado pelo TCP para definição das normas constitucionais de eficácia plena com aplicação direta e imediata parte da localização dos artigos no texto constitucional e da classificação imposta ao grupo circunscrito na primeira parte da Constituição, parte dogmática, independentemente de sua substância ou redação, enquanto para todos os demais dispositivos, ou seja, os outros duzentos e sessenta e um artigos restantes seriam indispensáveis à promulgação de lei de aplicação normativa (espécie normativa não prevista constitucionalmente e inédita até o referido PL) para que tivesse eficácia independentemente do conteúdo que a Constituição apresente.

0 TCP também atribuiu aos dispositivos constitucionais dogmáticos tanto efeitos positivos como negativos, ou seja, suficientes a revogar tudo que lhe fora contrário e impor limites ao legislador ordinário na produção de futuras leis que contrarie a CPB. Contudo, na decisão proferida pelo TCP na declaração no 003/2013, os mesmos efeitos não foram estendidos aos dispositivos inseridos nas partes orgânicas da Constituição boliviana de 2009. Assim todos os dispositivos constitucionais não dogmáticos inseridos na primeira parte da CPB de 2009, além de necessitarem de lei a lhes conceder aplicação normativa, também não possuiriam efeitos negativos ${ }^{29}$ abrindo, assim possibilidade

28. "Não é obviamente qualquer não-tratamento de um determinado assunto constitucional que faz surgir a lacuna a ser colmatada por via de integração.Esta só pode surgir naquelas hipóteses em que o próprio Texto Maior dá lugar a um vazio normativo, isto é: quando do contexto da lei fundamental se extrai que certas hipóteses deveriam ter sido reguladas, mas não foram. Não há possibilidade de preenchê-las por via de interpretação, ainda que extensiva, dos preceitos existentes" (BASTOS, 2010, p. 66)

29. "Dentro de ese marco, al evidenciarse que los cinco preceptos de redefinição parcial da Constituição de forma diferente daquelas previstas no art. 411, II, que exige procedimento restrito para realização de reforma parcial da parte não dogmática.

A decisão proferida alterou a posição hierarquicamente superior da Constituição, tornado esta, até então compreendida quanto à estabilidade como rígida, em virtude do disposto no art. 411 da CPB, em semirrígida, pois, segundo o TCP, o legislador ordinário inserido na Assembleia Legislativa Plurinacional, em virtude de sua natureza democrática e plural da instituição, melhor representaria a vontade do povo.

Apesar do discurso aparentemente deferente à decisão legislativa, a declaração de constitucionalidade do art. $4^{\underline{0}}$ do Projeto de Lei, convertido na Lei no 381 , de 21 de maio de 2013, Lei de Aplicação Normativa, atendeu aos interesses específicos do chefe do Executivo por meio da flexibilização da Constituição, possibilitando a candidatura e eleição do Presidente e Vice-Presidente da República para o terceiro mandato consecutivo, o segundo no marco do novo Estado boliviano (2015-2020).

A posição pronunciada pelo TCP teve por efeito a relativização da primazia constitucional prevista no art. 411.1 da CPB, cuja proteção constitui dever funcional e missão institucional do Tribunal, ao flexibilizar parcialmente a estabilidade dos dispositivos constitucionais em contradição ao art. 411.2 da Constituição boliviana de 2009 .

O desejo de perpetuação no poder manifesto pelo MAS e a posição do TCP submisso aos interesses secundários do governante relativizou a supremacia constitucional que constitui elemento essencial e indispensável ao novo constitucionalismo democrático latinoamericano sendo admitido, nesta perspectiva, como instrumento normativo capaz de frear

de aplicación normativa desarrollados en el proyecto de ley constituyen elementos que hacen a la parte orgánica de la Constitución, sus contenidos no sólo que pueden, sino que deben ser desarrollados mediante ley que emane del órgano de legitimidad popular, como es la Asamblea Legislativa Plurinacional; es decir, el constituyente derivado, aspecto absolutamente armónico con el orden constitucional, no sólo porque responde a la naturaleza jurídica de las disposiciones insertas en la parte orgánica de la Norma Suprema, sino porque materializa sus contenidos cumpliendo con la voluntad del constituyente originário" (BOLIVIA, 2013). 
efetivamente a força Executiva sempre em destaque na América Latina.

A decisão proferida pelo TCP não encerrou o assunto sobre a reeleição do presidente Evo Morales, se tratando apenas de mais um capítulo na intenção do governante em se manter no poder ainda que isso significasse a fragilização do texto constitucional e das instituições de poder, pois em fevereiro de 2016, ou seja, no curso de seu terceiro mandato, Evo Morales promoveu referendo buscando retirar da CPB o impedimento de uma eventual quarta candidatura sequencial ao cargo de presidente da República.

Todavia, ainda que tenha sido eleito há pouco tempo para o seu terceiro mandato, surpreendentemente, Evo Morales não conseguiu a aprovação que desejava junto aos eleitores bolivianos, afirmando Helena Argirakis que tal fato se deu em virtude de denuncias de corrupção (Arkonada, 2018).

Mesmo diante da derrota no referido referendo, parlamentares do partido político do presidente da República (MAS) ingressaram com Ação de Inconstitucionalidade Abstrata (AIA) pretendendo a declaração de inconstitucionalidade de dispositivos da Lei de Regulamentação Eleitoral ${ }^{30}$ (Lei no 26, de 30 de julho de 2010), assim como a inaplicabilidade de artigos constitucionais ${ }^{31}$ que restringiam a reeleição em virtude do disposto no art. 23, 29 e 29, todos da Convenção Americana de Direitos Humanos.

Em decisão proferida em 28 de novembro de 2017, por meio da sentença no 84, o TCP declarou haver hierarquia entre os ordenamentos que compõem o bloco de constitucionalidade, que, por sua vez, é formado pela Constituição, Tratados Internacionais de Direitos Humanos e Normas de Direito Comunitário, estes últimos ratificados pelo país, conforme anunciado pelo art. 410. II CPB.

A hierarquia declarada pelo TCP concedeu aos Tratados Internacionais de Direitos Humanos status de norma supraconstitucional devendo, em caso de conflito aparente de normas, prevalecer esta quando garanta a maior e mais ampla prevalência dos Direitos Humanos.

30. Art. 52, III, art. 64, LXV, LXXI, LXXII.

31. Art. 156, art. 168, art. 285. II e art. 288.
Ainda em desenvolvimento ao raciocínio exposto, concluiu o TCP que os Tratados Internacionais de Direitos Humanos gozam de grau superior inclusive estando hierarquicamente acima da própria Constituição, sobre a qual se opera o controle de convencionalidade, restando prevalente o controle de constitucionalidade somente frente a normas infraconstitucionais, sob pena de não se efetivar os pactos internacionais (TCP, 2017: 16-17).

Executando interpretação sistemática não apenas do texto constitucional, mas de todo o bloco de constitucionalidade, inclusive sentenças proferidas pela Corte Internacional de Direitos Humanos, somado, mais uma vez, ao atendimento integral dos desejos do chefe do executivo, a Corte Constitucional boliviana determinou a aplicação preferencial da Convenção Americana de Direitos Humanos em detrimento da norma constitucional por ser aquela norma mais favorável em relação aos Direitos Políticos, declarando também, em ato contínuo, a inconstitucionalidade das normas infraconstitucionais apontadas na AIA (TCP, 2017: 79) pelo MAS.

0 controle de convencionalidade realizado sobre a CPB abriu a possibilidade de Evo Morales (MAS) candidatar-se e eventualmente reeleger-se sucessivamente sem qualquer limite, algo capaz de colocar em xeque inclusive a democracia diante de possível ausência de alternância de forças políticas executivas, ampliando o hipertrofismo do executivo causando desequilíbrio institucional e, novamente, ameaçar as bases do novo constitucionalismo democrático na região.

Aberta a possibilidade de candidata-se mais uma vez, Evo Morales e Garcia Linera (MAS) novamente concorreram ao cargo eletivo para Presidente e Vice-presidente da república respectivamente, vindo, depois de tumultuada apuração de votos, a serem eleitos no primeiro turno para o quarto mandato consecutivo.

A oposição liderada por Carlos Mesa do partido Frente Revolucionario de Izquierda (FRI) passou a questionar o resultado, enquanto demais opositores foram para as ruas protestar contra 0 resultado, apontando a existência de fraudes na apuração.

Diante da grande pressão dos opositores, em 30 de outubro de 2019, após dez dias da 
votação que elegeu novamente Evo Morales (MAS), o governo boliviano assinou acordo com a Secretaria-Geral da Organização dos Estados Americanos (OEA) conferindo autorização para analisar a integridade eleitoral das eleições realizadas, vindo o Governo a comprometer-se ao fornecimento de documentos e informações necessárias para realização de auditoria adequada na contagem oficial de votos (OEA, 2019b:1).

Em 10 de novembro de 2019, a OEA publicou resultado parcial da auditoria sobre as eleições ocorridas em 20 de outubro do mesmo ano, concluindo preliminarmente que a avaliação realizada sobre a tecnologia; guarda, manutenção e integralidade de informações e documentos; bem como projeções estatísticas indicam sérias irregularidades que podem ter influenciado no resultado das eleições diante de fraudes e inexistência de informações suficientes para confirmar a vitória de Evo Morales e Garcia Linera (MAS) já no primeiro turno (OEA, 2019b: 13).

Diante da inviabilidade de conferência e indicativos de fraude, a OEA sugeriu novo processo eleitoral supervisionado por novas autoridades eleitorais com a finalidade de garantir o resultado fidedigno das eleições (OEA, 2019b: 13).

A publicação do relatório produzido pela OEA trouxe grande instabilidade política à Bolívia (OEA, 2019a, s/p), sendo esta intensificada com renúncia do Presidente e de todos os demais membros políticos que compreendem a linha sucessória presidencial nos termos do art. 169, inciso I da $\mathrm{CPB}^{32}$, sob a justificativa de ameaças promovidas pela polícia e forças armadas.

Diante das vacâncias, surpreendentemente, a Segunda-vice Presidente do Senado, Jeanine Añez pertencente ao partido Plan Progreso para Bolivia - Convergencia Nacional (PPB-NC), que fazia oposição ao governo de Evo Morales (MAS), se auto-proclamou Presidente da República em infringindo o art. 161, inciso $\mathrm{III}^{33}$ da $\mathrm{CPB}$, que

32. Artículo 169.

I. En caso de impedimento o ausencia definitiva de la Presidenta o del Presidente del Estado, será reemplazada o reemplazado en el cargo por la Vicepresidenta o el Vicepresidente y, a falta de ésta o éste, por la Presidenta o el Presidente del Senado, y a falta de ésta o éste por la Presidente o el Presidente de la Cámara de Diputados. En este último caso, se convocarán nuevas elecciones en el plazo máximo de noventa dias (Bolívia, 2009).

33. Artículo 161. Las Cámaras se reunirán en Asamblea exige a admissão pela Assembleia Legislativa Plurinacional da renúncia para configurar a vacância do cargo; contrariando também ao art. 169, inciso I da CPB, já que o cargo até então ocupado pela Segunda Vice-Presidente não compunha a linha sucessória da presidência; e ainda contrariando o disposto no art. 41, alínea a do Regulamento Geral da Câmara dos Senadores ${ }^{34}$, que atribui competência ao Segundo VicePresidente do Senado apenas para representação em caso de impedimento e não sucessão definitiva ou temporária.

As ações promovidas pelo MAS com a finalidade de perpetuar Evo Morales no cargo de Presidente, contando com a subserviência das demais instituições de poder, assim como a a atual manobra de dirigida à tomada de poder de forma ilegal, ilegítima e súbita protagonizada por autoridade alojada no poder às expensas da Constituição, independentemente das causas e dos fins políticos que a motivaram, além de caracterizar golpe de Estado (BONAVIDES, 2019: 454), evidenciam as fragilidades institucionais do Estado Plurinacional e demonstram o histórico avanço e retrocesso do constitucionalismo latino-americano.

\section{CONCLUSÃO}

As experiências constitucionais desenvolvidas na Europa e nos Estados Unidos da América, concebidos como hegemônicas e aplicáveis a todo o mundo civilizado, centrada na uniformidade e universalidade monista, limitadora da soberania estatal e popular, foram impostas aos países latino-americanos desconsiderando a cultura, história e costumes dos povos que habitavam com exclusividade a parte sul do continente americano antes da colonização ibérica.

A descolonização da América Latina no século XIX não foi capaz de trazer independência

Legislativa Plurinacional para ejercer las siguientes unciones, además de las señaladas en la Constitución:

(...)

3. Admitir o negar la renuncia de la Presidenta o del Presidente del Estado, y de la Vicepresidenta o del Vicepresidente del Estado (BOLIVIA, 2009).

34. Artículo 41. (Atribuciones de la Segunda Vicepresidencia) Son atribuciones de la Segunda Vicepresidenta o Segundo Vicepresidente: a) Reemplazar a la Presidenta o Presidente y a la Primera Vicepresidenta o Primer Vicepresidente, cuando ambos se hallen ausentes por cualquier impedimento (SENADO, 2012). 
epistemológica às ex-colônias que sofreram e sofrem influências de teorias hegemônicas monistas, que, inadequadas à região, acumulam insucessos repedidos capaz de causar instabilidade política e jurídica aos países do subcontinente.

O novo constitucionalismo democrático latino-americano reconhece que as tentativas de se implantar no subcontinente americano as experiências do Norte, não se mostraram adequadas para a região, sendo impostergável o acolhimento, reconhecimento e integração de povos e nações colocadas à margem do sistema, assim como sua cultura, instituições e concepções políticas, jurídicas, econômicas, sócias, religiosas e de bem estar.

Entretanto, o desenvolvimento do novo constitucionalismo democrático latino-americano na região não se dá de maneira uniforme, sendo apontado o Estado Plurinacional boliviano como o resultado mais agudo do movimento constitucional desenvolvido na América-Latina, diante da tentativa de superação monista e apresentação de concepções teóricas realmente inovadoras.

Inserido em um novo constitucionalismo adequado a região, o Estado Plurinacional da Bolívia buscou superar anos de cultura colonialista, exclusão de grande parcela da população por meio da equalização das diversidades culturais que, quando ignoradas, repercutem de forma conflituosa na estrutura das instituições democráticas de poder, assim como nas demais arenas políticas e jurídicas.

As desafiadoras pretensões do Estado boliviano refundado são alvos permanentes de ataques promovidos pela elite oligárquica desejosa do controle político-estatal excludente e tradicionalmente dominante, e, também, da ambição antidemocrática e contraditória de perpetuação no poder daqueles que iniciaram a luta por maior espaço e democracia.

0 confronto entre essas duas manifestas forças de poder político fragilizam as instituições democráticas do Estado Plurinacional boliviano e a proposta de adequação constitucional engendrada pelo novo constitucionalismo democrático latino-americano, nutrindo e mantendo a instabilidade no local e o autoritarismo histórico na região, contrário assim aos anseios de uma teoria constitucionalista de adequação como a democrática latino-americana.

A refundação do Estado boliviano em um Estado plurinacional que ampliou o reconhecimento da cosmovisão de parcela significante da população historicamente marginalizada não foi capaz de trazer instabilidade ao país que ainda sofre com ações políticas autoritárias e golpes que evidenciam a fragilidade das instituições democráticas como nos modelos de Estados anteriores experimentados, se mostrando incapaz de cessar o ciclo da estrutura de poder iniciado com a descolonização.

Todavia, compreendendo o novo constitucionalismo democrático latinoamericano e o próprio Estado plurinacional da Bolívia como modelos abertos à construção, as ações doravante promovidas pelas instituições apontarão decisivamente quais as alternativas e possibilidades para a desejada adequação constitucional e manutenção da estabilidade política e democrática da região.

\section{BIBLIOGRAFÍA}

- Arkonada, K. (2018). A Bolívia de Evo Morales e as eleições de 2019: é possível prever um 2019 de conflitos sociais, por isso é necessária a defesa do processo de mudança para além do bloco. Brasil de Fato. 31 ago. 2018. Disponível em: https://www.brasildefato.com. br/2018/08/31/a-bolivia-de-evo-moralese-as-eleicoes-de-2019/. Acessado em: 13 mai. 2019.

- Alves, F. B. (2013). Constituição e participação popular: a construção histórico-discursiva do conteúdo jurídicopolítico da democracia como direito 
fundamental. Curitiba: Juruá, 2013.

- Avritzer, L. (2017a). Introdução. In: AVRITZER, Leonardo; GOMES, Lílian Cristina Bernardo; MARONA, Marjore Corrêa; DANTAS, Fernando Antônio de Carvalho (Org.). 0 constitucionalismo democrático latino-americano em debate: soberania, separação de poderes e sistema de direitos (pp. 7-15). Belo Horizonte: Autêntica.

- ------. (2017b) 0 novo constitucionalismo latino americano: uma abordagem política. In: AVRITZER, Leonardo; GOMES, Lílian Cristina Bernardo; MARONA, Marjore Corrêa; DANTAS, Fernando Antônio de Carvalho (Org.). O constitucionalismo democrático latino-americano em debate: soberania, separação de poderes e sistema de direitos. Belo Horizonte: Autêntica. p. 19-42.

- Bastos, C. R. (2010). Curso de Direito Constitucional. São Paulo: Malheiros.

- Bolivia. (1826). Constitución Política de Bolivia, de 19 de noviembro de 1826. Disponível em: http://www. gacetaoficialdebolivia.gob.bo/index.php/ normas/verGratis_gob2/153916. Acessado em: 17 jun. 2019.

- -----. (1967). Constitución Política de Bolivia, 02 de febrero de 1967. Disponível em: http://www.gacetaoficialdebolivia. g o b . b o / i n d e x . p h p / n o r m a s / descargarPdf/36208. Acessado em: 17 nov. 2019.

- ------. (1994). Reforma la Constitución Política del Estado: ley no 1.585, de 12 de agosto de 1994. Disponível em: http:// www.lexivox.org/norms / BO-L-1585. xhtml. Acessado em: 09 jun. 2017.

- ------. (2009). Constituición Política de Bolivia, de 07 de febrero de 2009 (CPB). Disponível em: http://www. gacetaoficialdebolivia.gob.bo/index.php/ normas/descargarPdf/36208. Acessado em: 17 nov. 2019.
- -------. (2019a). Decreto Supremo no 0048, de 18 de marzo de 2009. Disponível em: http://www.lexivox.org/norms/BODS-N48.xhtml. Acessado em: 17 nov. 2019.

- -------. (2010). Ley del Órgano Judicial: ley $n$ o 25,24 de junio de 2010. Disponível em: http://www.gacetaoficialdebolivia. gob.bo/index.php/normas/verGratis_ gob2/124671. Acessado em: 09 jun. 2017.

- -------. (2013). Ley de Aplicación Normativa: lei no 21 de mayo de 2013. Disponível em: http://www.lexivox.org/norms/BO-L-N381. pdf. Acessado em: 17 nov. 2019.

- -------. Cámara de Senadores. Reglamento General de 2012. Disponível em: https://web.senado.gob.bo/file/26113/ download?token=FPFWHtVV. Acessado em: 17 nov. 2019.

- --------. Tribunal Constitucional Plurinacional (TCP). (2013). Declaración Constitucional 003, decisión en 25 abr. 2013. Disponível em: http://www.tcpbolivia. bo/tcp/content/tcp-resolvi\%C3\%B3consulta-sobre-proyecto-de-ley-deaplicaci\%C3\%B3n-normativa. Acessado em: 15 nov. 2019.

- ------- ------. (2017). Sentencia constitucional plurinacional no 0084 , de 28 de noviembre de 2017. Disponível em: https://edwinfigueroag.files.wordpress. com/2017/12/sentencia-0084-2017tcp-bolivia-reeleccion-evo-morales.pdf. Acessado em: 17 nov. 2019.

- Bonavides, P. (2019). Ciência Política. São Paulo: Malheiros.

- BRASIL, República Federativa do Brasil, de 05 de outubro de 1988. Disponível em: http://www.planalto.gov.br/ccivil_03/ constituicao/constituicaocompilado.htm. Acessado em: 13 jun. 2017.

- CAMBI, Eduardo. Neoconstitucionalismo e neprocessualismo: direitos fundamentais, políticas públicas e protagonismo do Judiciário. São Paulo: Revista dos Tribunais. 2009. 
- Canotilho, J. J. G. (2003). Direito Constitucional e Teoria da Constituição. Coimbra: Almedina.

- Conferência Especializada Interamericana sobre Direitos Humanos. (1969). Convenção Americana de Direitos Humanos. Disponível em: http://www.planalto.gov.br/ccivil_03/ decreto/D0678.htm. Acessado em 27 mai. 2019.

- Dan, V. L. C. e Nascimento, D.C. (2016). Análises sobre o Tribunal Constitucional Plurinacional Boliviano. Direito e Práxis Revista, 7 (14): 350-375.

- Equador. (2008). Constitución de la República del Ecuador, de 28 septiembre 2008. Disponível em: http://www. asambleanacional.gov.ec/documentos/ constitucion_de_bolsillo.pdf. Acessado em 17 nov. 2019.

- Extra: notícias. (2007). Oposição diz que nova Constituição boliviana é ilegal. 09 abr. 2007. Disponível em: https://extra.globo. com/noticias/mundo/oposicao-diz-quenova-constituicao-boliviana-ilegal-642405. html?versao=amp. Acessado em: 07 jun. 2017.

- Ferejohn, J. e Pasquino. P. (2009). Tribunais constitucionais como instituições deliberativas. In: BIGONHA, Antônio Carlos Alpino; MOREIRA, Luiz (Org.). Limites do controle de constitucionalidade (pp. 4164). Rio de Janeiro: Lumen Juris.

- Fioravanti, M. (2007). Constitución: de la Antigüedad a nuestros días. Madrid: Trotta.

- Gargarella, R. (2015). La sala de máquinas de la Constitución: dos siglos de constitucionalismo en América Latina (1810-2010). Buenos Aires: Katz Editores.

- Gargarella, R. e Courtis, C. (2009). El nuevo constitucionalismo latino-americano: promessa e interrogantes. Santiago de Chile: CEPAL.

- GIL, A. C. (2008). Métodos e técnicas de pesquisa social. São Paulo: Altas.

- Gustin, M. B. de S. e Dias, M. T. F. (2002). (Re)pensando a pesquisa jurídica: teoria e prática. Belo Horizonte: Del Rey.

- INSTITUTO INTERNACIONAL PARA LA DEMOCRACIA Y LA ASISTENCIA ELECTORAL (IDEA). (2010). Nueva Constitución Política del Estado: conceptos elementares para subdesarrollo normativo. La Paz: Vicepresidencia del Estado.

- de constitucionalismo en América Latina (1810-2010). Buenos Aires: Katz Editores.

- Gargarella, R. e Courtis, C. (2009). El nuevo constitucionalismo latino-americano: promessa e interrogantes. Santiago de Chile: CEPAL.

- GIL, A. C. (2008). Métodos e técnicas de pesquisa social. São Paulo: Altas.

- Gustin, M. B. de S. e Dias, M. T. F. (2002). (Re)pensando a pesquisa jurídica: teoria e prática. Belo Horizonte: Del Rey.

- INSTITUTO INTERNACIONAL PARA LA DEMOCRACIA Y LA ASISTENCIA ELECTORAL (IDEA). (2010). Nueva Constitución Política del Estado: conceptos elementares para subdesarrollo normativo. La Paz: Vicepresidencia del Estado.

- Morales, Evo. (2009). Para que nunca más seamos excluidos. Discurso de introdução à Constituição Política da Bolívia. Disponível em: https://pt.scribd.com/ document/109834527/CONSTITUCIONPOLITICA-DEL-ESTADO-DE-BOLIVIA. Acessado em: 09 jun 2019.

- Machicado, J. (2009). Derecho constitucional boliviano. Sucre: USFX.

- Mosiño, E. C. L. (2017). Indigenismo e Constituição na Bolívia: um enfoque desde 1990 até os dias atuais. In: Avritzer, L.; Gomes, L.; Marona, M. C. e Dantas, F. A. de C. (Org.). 0 constitucionalismo democrático latino-americano em debate: soberania, separação de poderes e sistema de direitos (pp. 287-312). Belo Horizonte: Autêntica.

- Pastor, R. A. V. e Dalmau, R. M. (2010). Aspectos generales del nuevo constitucionalismo latino-americano. Quito: Corte Constitucional de Ecuador. 
- ORGANIZAÇÃOO DOS ESTADOS AMERICANOS (OEA). (2019a). Declaração da Secretaria- Geral da OEA sobre a situação na Bolívia. Disponível em: https:// www.oas.org/pt/centro_midia/nota_imprensa.asp?sCodigo $=\mathrm{P}-101 / 19 . \quad$ Acessado em: 17 nov.

- -------. (2019b). Preliminary findings: report to the general secretariat. Disponível em: http://www.oas.org/documents/ eng/press/Electoral-Integrity-AnalysisBolivia2019.pdf. Acessado em: 17 nov.

- Horta, R. (2017). Controle concentrado de constitucionalidade: elemento estrutural de validade das decisões sobre política pública. Curitiba: Juruá, 2017.

- Sampaio, J. A. L. (2013). Teoria da constituição e dos direitos fundamentais. Belo Horizonte: Del Rey.

- Santander, D. C. (2012). Un recorrido por la Historia de las marchas indígenas. Expresiones de Sociales, (1): 16 - 19.

- Santos, Boaventura de S. (2010). Refundación del Estado en América Latina: perspectivas desde una epistemología del Sur. Lima: Instituto Internacional de Derecho y Sociedad; Programa Democracia y Transformación Global.

- -----. (1988). Uma cartografia simbólica das representações sociais: prolegômenos a uma representação pós-moderna do Direito. Revista Crítica de Ciências Sociais, (24): 139 - 172.

- Sarlet, I. W. (2007). A Eficácia dos Direitos Fundamentais. Porto Alegre: Livraria do Advogado.
- Serrano, P. E. A. P. (2016). Autoritarismo e golpes na América Latina: breve ensaio sobre jurisdição. São Paulo: Alameda.

- Silva, M. M. (2010).Jurisdição Constitucional no MERCOSUL. Observatório da Jurisdição Constitucional, (4): 1-19.

- Silva Júnior, G. L. da. (2014). A constituição do Estado Plurinacional da Bolívia como um instrumento de hegemonia de um projeto popular na América Latina. Tese (Doutorado em Direito). Universidade de Brasília, Brasília.

- Soares, E. e Ladeira, R. (2013). A Supremacia Executiva e a Coadjuvação Legislativa e Judiciária: experiências latino-americanas na separação dos Poderes do Estado. In: IV ENCONTRO DE ADMINISTRAÇÃO POLÍTICA PARA O DESENVOLVIMENTO DO BRASIL. (pp. 01-10). Vitória da Conquista: UESB.

- Tarrega, M.C.V.B; Freitas, V.S. Novo constitucionalismo democrático latino-americano: paradigma jurídico emergente em tempos de crise paradigmática. Avritzer, L.; Gomes, L.; Marona, M. C. e Dantas, F. A. de C. (Org.). O constitucionalismo democrático latinoamericano em debate: soberania, separação de poderes e sistema de direitos (pp. 97-116). Belo Horizonte: Autêntica.

- Vicentino, C. e Dorigo, G. (2013). História geral e do Brasil. v. 2. São Paulo: Scipione.

- Wolkmer. A.C. (2009). Pluralismo Jurídico y constitucionalismo brasileño. In: Bonilla, D.; Pavel. H. e Valer-Bellota. El (Neo) Constitucionalismo Multicultural en América Latina. Espanha: Oñati. 